\title{
Osteofibrous Dysplasia
}

National Cancer Institute

\section{Source}

National Cancer Institute. Osteofibrous Dysplasia. NCI Thesaurus. Code C53970.

A benign, usually self-limited fibro-osseous lesion of the bone that affects infants and children. It usually arises from the cortical bone of the anterior mid-shaft of the tibia. Patients usually present with swelling or painless bowing of the tibia. Progression to adamantinoma has been reported in some cases. 